\title{
COST-EFFECTIVENESS OF HLA-B*5701 PROSPECTIVE GENETIC SCREENING OF HYPERSENSITIVITY TO ABACAVIR
}

\author{
KUBAEVA M B ${ }^{1 *}$, GUSHCHINA J Sh${ }^{1}$, LOSKUTOVA E E $^{2}$ \\ ${ }^{1}$ Department of General and Clinical Pharmacology, Medical Institute, Peoples' Friendship University, Moscow, Russian Federation, \\ Russian. 'Department of Management and Economics of Pharmacy, Medical Institute Peoples' Friendship University, Moscow, Russian \\ Federation, Russian. Email: kubaevamariyam@mail.ru \\ Received: 12 September 2017, Revised and Accepted: 17 November 2017
}

ABSTRACT

Objective: This study was conducted to evaluate the use of genetic tests, before prescribing drugs to reduce not only the level of side effects but also the costs associated with changing therapy. In this paper, the authors analyze the economic efficiency of HLA*5701 prospective screening of hypersensitivity to abacavir (ABC) in the treatment of HIV-infected patients.

Methods: A retrospective study was conducted among HIV-infected patients taking first-line antiretroviral therapy and further, based on the results obtained with the $\mathrm{ABC}$-hypersensitivity reactions, analyzed the costs that affect on healthcare system.

Results: In the study group of HIV-infected patients, most of the cases belonged to a young, socially active part of the population. Among the study population of patients ( $\mathrm{n}=637), 171$ patients were assigned $\mathrm{ABC}$-containing antiretroviral therapy. An increase in costs was found in $67 \%$ of cases when $\mathrm{ABC}$-containing first-line therapy was replaced due to the occurrence of undesirable reactions.

Conclusion: The results show that, using this screening, we could reduce the costs associated with replacement therapy.

Keywords: HIV, Abacavir, HLA*5701 prospective screening, economic efficiency.

(C) 2018 The Authors. Published by Innovare Academic Sciences Pvt Ltd. This is an open access article under the CC BY license (http://creativecommons. org/licenses/by/4. 0/) DOI: http://dx.doi.org/10.22159/ajpcr.2018.v11i2.22519

\section{INTRODUCTION}

Abacavir (ABC) is an antiretroviral drug belonging to the class of nucleoside reverse-transcriptase inhibitors [1]. It has proven effective in first-line antiretroviral therapy (ART) regimens [2]. However, one of the life-threatening side effects of antiretroviral drugs is the development of hypersensitivity reaction. There was a significant association between the development hypersensitivity reaction to $\mathrm{ABC}$ and the presence of the HLA-B*5701 allele. In this regard, it was recommended to include screening typing on the HLA-B* 5701 marker in routine clinical practice and to conduct it before the appointment of $\mathrm{ABC}[3]$.

Pharmacogenetic testing is not widely used in routine clinical practice to optimize the drug choice or clinical treatment [3]. This gap between scientific knowledge and clinical application can be explained by the fact that successful inclusion of the pharmacogenetic test in broad practice requires a combination of highly effective drugs and reliable laboratory tests with an effective strategy for including testing in a broad clinical practice.

Symptoms of hypersensitivity reactions to $\mathrm{ABC}$ include fever, rash, constitutional symptoms, gastrointestinal symptoms, and respiratory symptoms, which become more severe with the continued use of ABC. Immediate and permanent discontinuation of $\mathrm{ABC}$ is mandatory, leading to a rapid disappearance of symptoms. The subsequent readministration of $\mathrm{ABC}$ is contraindicated, as it may lead to a more serious, rapid, and potentially life-threatening reaction.

Studies have shown that adherence to ART raises the quality of life among HIV-infected patients, but lifelong adherence to therapy is required [4]. To ensure more safe and effective treatment of patients at all levels of the health system, continuous evaluation and monitoring of the harm and benefits of ART are required [5]. Conducting genetic screening is of interest not only from the standpoint of preventing the development of side effects but also to reduce the cost of therapy.

Thus, in a number of studies, it has been shown that prospective HLA-B* 5701 screening before initiation of ABC therapy reduces the cost of therapy $[6,7]$. In a study using mathematical modeling, it was shown that the extensive use of HLA-B* 5701 screening before the administration of $\mathrm{ABC}$ to HIV-infected patients may result in cost savings or a small additional expenditure for the health system, which, however, is counterbalanced by a reduction in the incidence of side effects on $\mathrm{ABC}[7,8]$.

Based on data from a US-based study, the use of prospective HLA-B* 5701 screening is effective in choosing to start antiretroviral therapy, with the \$/QALY indicator (cost of 1 year of life with a quality of life corresponding to absolute health) of $\$ 50,000$, which testifies to the marginal effectiveness. Nevertheless, the cost-effectiveness ratio largely depends on the effectiveness of therapy with regimens including $\mathrm{ABC}$ or alternative regimens including tenofovir, taking into account the cost of the drugs themselves and also taking into account the cost of carrying out the HLA-B* 5701 test itself [9-12].

To improve the effectiveness of treatment, a useful method was the economic evaluation in health research [13]. Thus, the question of the pharmacoeconomic efficiency of using the prospective HLA-B* 5701 screening needs a deeper study, which determined the purpose and objectives of our study.

\section{METHODS}

To estimate the costs associated with ABC-hypersensitivity reactions, we performed a retrospective standardized assessment of clinical suspicious cases of them in the specific population and further, based on the results obtained with the $\mathrm{ABC}$ - hypersensitivity reactions, analyzed the costs that effect on health care system. The sources of 
information were 637 case histories of patients with HIV infection. The main criterion for including patients in the cohort was the presence of an established diagnosis of HIV infection. The criteria for including of the second level were adopted:

- $\quad$ Age over 18;

- Non-participation in clinical trials during the reviewed period,

- The primary appointment of antiretroviral therapy, including ABC-containing therapy.

To estimate the costs associated with changing the starting ABCcontaining therapy to an alternative treatment regimen, we took into account the difference in their cost. To get this purpose, a summary table was compiled to reflect all substitutions of ABC-containing ART regimens for each patient in the study group, and cost changes were also assessed depending on the reason for the modification of therapy. This methodical approach allowed to estimate the share of each component in the cost structure for the change of $\mathrm{ABC}$ containing therapy and the further possibility to optimize this type of burden.

To estimate the costs associated with the use of the HLA-B* 5701 test, the cost of it was carried out. The cost of two-, three-, or fourcomponent ART regimens was determined by adding the cost of each individual antiretroviral preparation in the treatment regimen over the same period of time.

\section{RESULTS}

Analysis of the epidemiological indicators of the population studied revealed the prevalence of men about $61 \%$ and $39 \%$ of women. Unsecured sex (of which, heterosexual $47.6 \%$ and homosexual $12.4 \%$ ) was indicated as the main risk factor for infection in $60 \%$ of cases. Injecting drug use as the main risk factor for infection was observed in $24.5 \%$ of the study population. However, it should be noted that it is possible that not all patients openly reported injecting drug use (Table 1)

Thus, it can be concluded that, in the study group, the young, socially active part of the population was infected with HIV infection in most of the cases. Heterosexual sexual intercourse was noted as the most frequent route of infection.

During the pharmacoepidemiological study, it was found that 474 people $(74.4 \%)$ were prescribed starting ART, of which 171 patients had initiation therapy with $\mathrm{ABC}$ containing in a specific study population of HIV patients on dispensary observation ( $n=637$ people).

Among the analyzed population, $5.5 \%$ of patients reported the development of adverse reactions after the appointment of starting $\mathrm{ABC}$-containing therapy.

Analysis of substitution therapy showed that the greatest increase in cost was observed using combinations ritonavir (RTV)/presista and combivir (AZT/lamivudine [3TC]/issetress. The combination of $\mathrm{ABC} / 3 \mathrm{TC} /$ atazanavir/RTV was not included in 10 most common regimens for initiation of $\mathrm{ABC}$ therapy, but most often caused side effects $(11.5 \%)$. Perhaps, the multicomponent scheme of this scheme led to the development of side effects, which indicates that side effect can cause another drug.

When analyzing all $\mathrm{ABC}$-containing start-up therapy regimens that included the replacement of the drug due to the occurrence of undesired reactions, a total increase in expenditure was found in $67 \%$ of cases on average by 54164.6 rubles.

At the same time, the cost of HLA-B* 5701 tests for patients who had to change $\mathrm{ABC}$-containing therapy due to adverse reactions would be 5201.3 rubles. Moreover, only 1 scheme of 26 cases was canceled due to the development of side effects, which corresponded to the clinical picture of $\mathrm{ABC}$-hypersensitivity reactions (Table 2).
Table 1: Sociodemographic distribution of the study population

\begin{tabular}{ll}
\hline Variables & № (\%) \\
\hline Sex & \\
Male & $391(61.4)$ \\
Female & $246(38.6)$ \\
Socioeconomic status & \\
Working & $425(66.7)$ \\
Workless & $52(8.2)$ \\
Student & $13(2.0)$ \\
Not reported & $147(23.1)$ \\
Path of infection & \\
Injecting drugs & $156(24.5)$ \\
Hetero & $303(47.6)$ \\
Homo & $79(12.4)$ \\
Homo, hetero & $4(0.6)$ \\
No data & $84(13.2)$ \\
Other & $11(1.7)$ \\
\hline
\end{tabular}

Table 2: The scheme was canceled due to the development of side effects, which corresponded to the clinical picture of the reaction of $\mathrm{ABC}$ hypersensitivity

\begin{tabular}{llll}
\hline First-line therapy & $\begin{array}{l}\text { Cost, } \\
\text { rub. }\end{array}$ & $\begin{array}{l}\text { Replacement } \\
\text { therapy }\end{array}$ & $\begin{array}{l}\text { Cost, } \\
\text { rub. }\end{array}$ \\
\hline ABC/Epivir (3TC)/ATZ & 11558.4 & FAZT/3TC/ATZ & 8612.4 \\
\hline
\end{tabular}

Rub: Rubles. ABC: Abacavir, ATZ: Reataz, FAZT: Fosfazide, 3TC: Lamivudine, ATZ: Atazanavir

This indicates the pharmacoeconomic inefficiency of replacement therapy due to $\mathrm{ABC}$-associated undesirable side reactions.

\section{DISCUSSION}

The results of our study serve as an additional rationale for the introduction of the HLA-B*5701 hypersensitivity test for ABC at the federal level to prevent inappropriate changes in therapy, not only clinically but also economically.

The data obtained are an additional justification for the need to strengthen measures to prevent side effects, including prospective HLA-B*5701 screenings before the appointment of ABC, which together will reduce the high costs of frequent replacement of ART.

Thus, this analysis shows the current significance of the HLA-B*5701 hypersensitivity test for $\mathrm{ABC}$, not only to provide quality pharmaceutical care to HIV-infected patients but also to reduce the costs associated with replacement therapy.

\section{CONCLUSION}

Antiretroviral therapy helps not only to prolong but also to improve the quality of life of HIV-infected patients. The pharmacoeconomic study of using genetic tests before the appointment of therapy has a huge impact on the rational use of drugs, reducing the development of side effects. This research has a great practical importance of controlling medical costs and reducing them not only for patients but also for a society.

\section{AUTHORS CONTRIBUTIONS}

All the author have contributed equally.

\section{CONFLICT OF INTERESTS}

Declared none.

\section{REFERENCES}

1. Kauf TL, Farkouh RA, Earnshaw SR, Watson ME, Maroudas P, Chambers MG, et al. Economic efficiency of genetic screening to inform 
the use of abacavir sulfate in the treatment of HIV. Pharmacoeconomics 2010;28:1025-39.

2. Castillo SA, Hernandez JE, Brothers CH. Long-term safety and tolerability of the lamivudine/abacavir combination as components of highly active antiretroviral therapy. Drug Saf 2006;29:811-26.

3. Yu AL. HIV and AIDS: National Guidelines/Acad. In: Pokrovsky, RV, editor. Preparation Under Aegis of Association Honey. On-in Quality. Moscow: GEOTAR-Media; 2013. p. 606.

4. Deepak MS, Kamath VG, Nair S, Kamath A. Does providing free antiretroviral therapy ensure optimal adherence among people living with HIV/AIDS? Asian J Pharm Clin Res 2016;9:172-5

5. Kumar AP, Parthasarathi G, Sudheer AP, Mothi SN, Swamy VH, Rao S. Incidence and risk factors of renal impairment in HIV-1 infected patients receiving tenofovirbased antiretroviral therapy in a South Indian hospital. Int J Pharm Pharm Sci 2017;9:152-5.

6. Max B, Sherer R. Management of the adverse effects of antiretroviral therapy and medication adherence. Clin Infect Dis 2000;28:34-46.

7. Wolf E, Blankenburg $\mathrm{M}$, Bogner JR, Becker W, Gorriahn D, Mueller MC, et al. Cost impact of prospective HLA-B*5701 screening prior to abacavir/lamivudine fixed dose combination use in Germany. Eur J Med Res 2010;15:145-51.
8. Nieves Calatrava D, Calle-Martín Ode L, Iribarren-Loyarte JA, Rivero-Román A, García-Bujalance L, Pérez-Escolano I, et al. Costeffectiveness analysis of HLA-B*5701 typing in the prevention of hypersensitivity to abacavir in HIV+ patients in spain. Enferm Infecc Microbiol Clin 2010;28:590-5.

9. Wolf E, Stoll M, Becker-Andre M, Bogner J, Becker W, Gorriahn D, et al. Prospective HLA-B*5701 Screening for Abacavir Hypersensitivity Saves Costs, XVII. International AIDS Conference, Mexico City, Mexico. 2008. p. 3-8.

10. Hughes DA, Vilar FJ, Ward CC, Alfirevic A, Park BK, Pirmohamed M. Cost-effectiveness analysis of HLA B*5701 genotyping in preventing abacavir hypersensitivity. Pharmacogenetics 2004;14:335-42.

11. Phillips KA, Veenstra DL, Oren E, Lee JK, Sadee W. Potential role of pharmacogenomics in reducing adverse drug reactions: A systematic review. J Am Med Assoc 2001;286:2270-9.

12. Schackman BR, Scott CA, Walensky RP, Losina E, Freedberg KA, Sax PE. The cost-effectiveness of HLA B*5701 genetic screening to guide initial antiretroviral therapy for HIV. AIDS 2008;22:2025-33.

13. Le PH, Tran QV, Vo TQ. A systematic review of hepatitis virus review studies: A case of health economic evaluation analysis. Int J Pharm Pharm Sci 2017;9:114-20. 